\begin{tabular}{|c|c|c|c|c|c|c|}
\hline \multirow{4}{*}{ [mpact Factor: } & ISRA (India) & 3.117 & SIS (USA) & $=0.912$ & ICV (Poland) & $=6.630$ \\
\hline & ISI (Dubai, UAE & $=0.829$ & РИНЦ (Russia) & $=0.156$ & PIF (India) & 1.940 \\
\hline & GIF (Australia) & $=0.564$ & ESJI (KZ) & $=5.015$ & IBI (India) & $=4.260$ \\
\hline & JIF & $=1.500$ & S.JF (Mor & $=5.667$ & OAJI (USA) & $=0.350$ \\
\hline
\end{tabular}

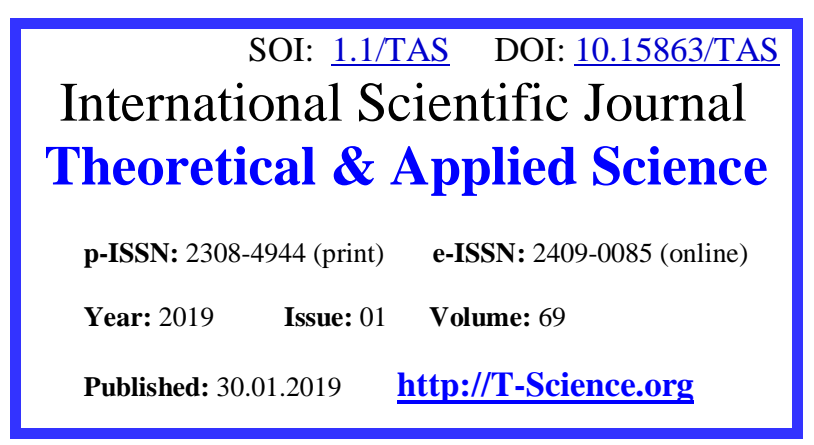

SECTION 31. Economic research, finance, innovation, risk management.
QR - Issue

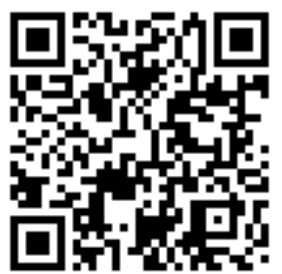

QR - Article

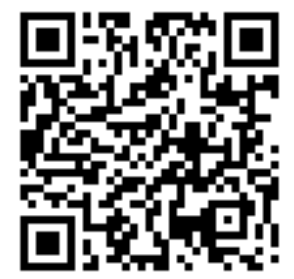

Saadat Askar Gumbataliyeva $\mathrm{PhD}$ in economics, senior lecturer of Sumgait State University Sumgait, Azerbaijan Republic.

Eldeniz Mazahir Maharramov $\mathrm{PhD}$ in economics, senior lecturer of Azerbaijan Cooperation University, Baku, Azerbaijan Republic

\title{
MODERN ASPECTS OF FORMATION AND DEVELOPMENT OF SOCIAL STRATEGY IN THE CONDITIONS OF STRUCTURAL CHANGES OF ECONOMY
}

\begin{abstract}
Modern aspects of formation and development of social strategy in the conditions of structural changes of economy are discussed in the article. The essence of the modern aspects of social policy and social problems is analyzed. The transformation of social problems and social mechanisms under the influence of global change is considered. The features of the formation and development of social strategy in the period of structural reforms are revealed. The effects of institutional and structural changes on a country's social strategies are evaluated. The role of the state in balancing the mutual interests of society and the economy is noted. The importance of state regulation of optimization of social policy and its economic mechanisms, contributing to a significant increase in the vital state of the population, is revealed. The factors that ensure the harmonious development of society and the economy, the disclosure of human potential, raising the level of the education system and health care are analyzed. A number of proposals and recommendations on the modern aspects of formation and development of social strategy in the conditions of structural changes of economy are summarized and given.

Key words: modern aspects of social strategy, problems of formation of social strategy, balance of social policy and economic development of the country, social strategy in the context of structural changes, social strategies in the context of global impacts, social strategies taking into account the interests of society and the economy.
\end{abstract}

Language: Russian

Citation: Gumbataliyeva, S. A., \& Maharramov, E. M. (2019). Modern aspects of formation and development of social strategy in the conditions of structural changes of economy. ISJ Theoretical \& Applied Science, 01 (69), 276-283.

Soi: http://s-o-i.org/1.1/TAS-01-69-38 Doi: crossef https://dx.doi.org/10.15863/TAS.2019.01.69.38

\section{СОВРЕМЕННЫЕ АСПЕКТЫ ФОРМИРОВАНИЯ И РАЗВИТИЯ СОЦИАЛЬНОЙ СТРАТЕГИИ В УСЛОВИЯХ СТРУКТУРНЫХ ИЗМЕНЕНИЙ ЭКОНОМИКИ}

Аннотация: В статье рассмотрены проблемы и вопросы современных аспектов формирования и развития социильной стратегии в условиях структурных изменений экономики. Анализировано сущность современных аспектов социальной политики и социальных проблем. Рассмотрено трансформации социильных проблем и социиальных механизмов под воздействием глобальных изменений. Раскрыто особенности формирования и развития социальной стратегии в период структурных реформ. Оченены влияния институцииональных и структурных изменений на социальные стратегии страны. Отмечены роли государства по сбалансированию взаимных интересов общество и экономики. Раскрыто важность государственного регулирования оптимизации сочиальной политики и его экономических механизмов, способствующий существенному повышению жизненного состояния населения страны. Анализированы 


\begin{tabular}{|c|c|c|c|c|c|c|}
\hline \multirow{4}{*}{ Impact Factor: } & ISRA (India) & $=3.117$ & SIS (USA) & $=0.912$ & ICV (Poland) & $=6.630$ \\
\hline & ISI (Dubai, UAE & $=0.829$ & РИНЦ (Russia & $=0.156$ & PIF (India) & $=1.940$ \\
\hline & GIF (Australia) & $=0.564$ & ESJI (KZ) & $=\mathbf{5 . 0 1 5}$ & IBI (India) & $=4.260$ \\
\hline & JIF & $=1.500$ & SJIF (Morocco & $=5.667$ & OAJI (USA) & $=0.350$ \\
\hline
\end{tabular}

факторы, обеспечивающие гармоничного развития общество и экономики, раскрытие человеческого потенциала, повышения уровня системы образования и здравоохранения. Обобщен и дан ряд предложений и рекомендаций по современным аспектам формирования и развития соииальной стратегии в условиях структурных изменений экономики.

Ключевые слова: современные аспекты сочиальной стратегии, проблемы формирования сочиальной стратегии, сбалансированность сочиальной политики и экономического развития страны, соииальная стратегия в условиях структурных изменений, соииальные стратегии в условиях глобальных воздействий, сочиальные стратегии с учетом интересов общество и экономики.

\section{Introduction}

В современных условиях основные механизмы, в том числе экономические механизмы социальной политики государства требует серьезные совершенствовании, с учетом новых глобальных, социальных и экономических вызовов. Социальные аспекты и механизмы охватывают основные сферы человеческой жизни и ее деятельность, в том числе условия жизни, трудовую деятельность и важные механизмы социальной ориентированности. Безусловно, государственная политика и стратегические подходы на этой сфере в первую очередь охватывают сферы труда, потребления, быта, образования, культуры и искусства, отдыха и охраны здоровья и все они в определенной степени оказывают социально-ориентированную поддержку человека в условиях рыночных отношений [1]. Кроме того, с целью реализации стратегических подходов в социальной сфере и формирования социальной стратегии обуславливает сбалансированности разных подходов и методов, в том числе экономическая, административная, законодательная и другие механизмы. Государство с помощью экономических подходов разрабатывает и формирует социальную стратегию, которое в конечном итоге поддерживают населению в решении многих проблем. В числе практичных экономически подходов и методов по формированию социальной стратегии государства больше всего отводиться место таким методам, как метод цены, экономические льготы, тарифы, налоги, пенсии, разные пособии, стипендии, заработная плата, доходы населения, множество видов социальных плат и другие формы государственной поддержки. Когда речь идет о стратегическом подходе формирования и развития социальной политики, подходов и стратегий в условиях трансформаций экономических процессов и в том числе структурных изменений в экономике, необходимо, прежде всего, оптимизировать и сбалансировать две важные компоненты развития экономики и социальная политика, только в этом случае можно обеспечить стабильное развитие одновременно экономику страны и общество, улучшить жизненное состояние страны, повысить потенциал по интенсивному решению социально- экономических проблем. Развитие экономики страны должно сопровождаться оптимизацией социальной политики и повышения эффективности основных механизмов социальной - экономической деятельности, которая могла бы обеспечить созданию соответствующих условий для материального и духовного развития граждан страны [2]. Такого рода социальной стратегии, считаем, что способны увеличить национальное богатство и в то же время стимулировать рациональность экономических процессов и хозяйственной деятельности, рост доходов граждан и в целом страны. Имея возможность постоянного роста своих доходов, граждане страны получит реальные ресурсы для развития полноценно здорового и образованного человека, способного и интеллектуального специалиста в своей выбранной сфере, который может внести свой вклад в развитию общества и страны. Более того, получив полноценную государственную поддержку и стабильную систему социальной защиты, граждане страны максимально выложат свои вклады, труды и интеллект для преобразования страны в сторону развитых стран и повышения конкурентоспособности [3]. В условиях трансформаций существующих механизмов экономических процессов и структурных изменений особо требуется новые принципы социальной политики и обновленные механизмы социальной стратегии страны. Это обусловлено с новыми вызовами времени и глобальных воздействий на экономических и социальных механизмов, которое используется ныне. На основе социальной стратегии должны крепко заложиться комплексные меры, которые способны обеспечить благоприятные условия жизни и труда населения с соблюдением социально справедливости и смягчения социальной напряженности, формирования максимально справедливой среды в обществе и повышения рациональности применяемых экономических механизмов в социальной сфере. Социальные стратегии должны отвечать принципам, нормам и мерам, стандартам и международным критериям по формированию и регулированию социально-экономических условий, обеспечивающих защиту граждан в ситуациях разного вида социальных рисков, которые наносит существенный ущерб 


\begin{tabular}{|c|c|c|c|c|c|c|}
\hline \multirow{4}{*}{ Impact Factor: } & ISRA (India) & $=3.117$ & SIS (USA) & $=0.912$ & ICV (Poland) & $=6.630$ \\
\hline & ISI (Dubai, UAE & $=0.829$ & РИНЦ (Russia) & $=0.156$ & PIF (India) & $=1.940$ \\
\hline & GIF (Australia) & $=0.564$ & ESJI (KZ) & $=\mathbf{5 . 0 1 5}$ & IBI (India) & $=4.260$ \\
\hline & JIF & $=1.500$ & SJIF (Morocco) & $=5.667$ & OAJI (USA) & $=0.350$ \\
\hline
\end{tabular}

гражданам, например, как негативные последствия безработиц, инфляция, неадекватность системы социальной защиты, инвалидность и другие. Реализация механизмов социальной стратегии и социальная защита граждан страны осуществляется по двум направлениям, то есть денежной (пособии, пенсии, субсидии, дотации) и натуральной форме (бесплатные государственные социальные механизмы, бесплатные школьное питание, обеспечение одеждой, питание детских домов, дом престарелых, приютов, бесплатные выдачи оборудований, скот, земли, других необходимых вещей и ценностей для ведения собственного дела, обеспечения само занятости). Кроме того, на основе социальной стратегии должны иметь стратегическое значение и место вопросы и проблемы качество жизни населения, прежде всего здоровья, безопасность труда и улучшение морально-психологического климата в обществе и экономики страны [4]. В целом социальная стратегия страны и его практические механизмы должны максимально охватить социальнонуждающихся граждан, у которых доходы находятся ниже установленного прожиточного минимума и не имеет возможность диверсифицировать свой доход [5].

\section{Materials and Methods}

Отметим, что проблемы и вопросы формирования социальной стратегии в условиях структурных изменений рассматривались в научных трудах и исследовательских работ ряд ученых, где основной упор делалось на важность оптимизации компонентов и инструментарий социально-экономических развитий страны с учетом сбалансированных интересов общество и экономики. Формирования системы стратегического управления социальноэкономического развития разных секторов экономики страны и с учетом расширения сферы услуг обуславливает комплексные и системные подходы по улучшению жизненного состояния населения и интенсификация развития национальной экономики, но для этого необходимо разработать стратегические подходы по сбалансированному развитию роста экономики и социальной сферы. Повышения установленных на основе сбалансированного ресурса-потребления темпов экономического роста, соответствующих особенностям деятельности и соразмерному уровню противодействия влиянию негативных факторов макро-, микросред возможно на основе формирования в системе стратегического управления функциональных стратегий и выбора альтернативной стратегии экономического роста. Стратегическое управление социальноэкономическим развитием отраслевых составляющих, их хозяйствующих субъектов сферы услуг должно свою роль функционального предназначения играть как инструмент противодействия влиянию негативных факторов, возникающих в неопределённом времени, в его прогнозируемых интервалах, на экономические результаты и эффективность долгосрочного развития социально-экономической системы [6]. Стратегические подходы социальным вопросам требует максимально объективного планирования и прогнозирования в ближайшем и долгосрочном периоде экономических и социальных аспектов, способствующей улучшения бытовых услуг населения, обеспечения интенсивного развития социального инфраструктуры и системы социальной защиты. Государство должно озаботиться о продуктивном размещении производительных сил и эффективности использования трудовых ресурсов путем привлечения экономических и природных ресурсов регионов страны, тем самым сформировывать потенциальные источники финансирования социальных проектов, создания новых рабочих мест для уменьшения безработицы и уровня бедности, построить сеть конкурентоспособных объектов инфраструктур и социального назначения, создать необходимые условия для духовного развития подрастающей поколении и в целом обществе, следить за доступность важных видов пищевых продукций, медицинских услуг и получения соответствующего образования населения страны.

Как мы отметили, региональный аспект и факторы сыграет немаловажную роль в совершенствовании механизмов управления социально-экономическими процессами, а так же в процессах формирования и развития социальной стратегии в целом. Дело в том, что основу системы государственного регулирования социально-экономических процессов составляют отношения по поводу перераспределения доходов и повышения эффективности использования региональных ресурсов с целью совершенствования структуры материального производства, улучшения состояния окружающей среды, развития социальной инфраструктуры [7]. Кроме того, необходимо учитывать другие факторы по совершенствованию важных механизмов социальной стратегии, таких как социально-экономический потенциал отдельных территорий и регионов, адекватность рабочей силы и рабочих мест, уровень доходов и потребительских расходов гражданин, уровень развития социальной сферы, в том числе наличие объектов социальной инфраструктуры, перечень и обеспеченность граждан страны услугами социальных назначений, мобильность, 


\begin{tabular}{|c|c|c|c|c|c|c|}
\hline \multirow{4}{*}{ Impact Factor: } & ISRA (India) & $=3.117$ & SIS (USA) & $=0.912$ & ICV (Poland) & $=6.630$ \\
\hline & ISI (Dubai, UAF & $=0.829$ & РИНЦ (Russia & $=0.156$ & PIF (India) & $=1.940$ \\
\hline & GIF (Australia) & $=0.564$ & ESJI (KZ) & $=\mathbf{5 . 0 1 5}$ & IBI (India) & $=4.260$ \\
\hline & JIF & $=1.500$ & SJIF (Morocco & $=5.667$ & OAJI (USA) & $=0.350$ \\
\hline
\end{tabular}

прозрачность и справедливость социальной системы страны.

Отметим, что формирования новых современных подходов и механизмов для развития социальной стратегии в условиях глобальных трансформаций социальноэкономических отношений и механизмов обуславливают комплексное рассмотрения финансового обеспечения и проблем капитального вложения к социально экономическому развитию страны. Необходимо разработать и реализовать более обоснованные и оптимальные модели развития социальной стратегии, которое охватывает механизмы стимулирования социально-экономического развития страны путем разработки и реализации целевых инвестиционных проектов и программ. Дело в том, что сложность и многообразия процессов социального развития, одновременное сбалансирование механизмов социальных и экономических проблем, требует объективную оценку осуществляемых государственных вложений по решению социально-экономических проблем. Более того, при подготовки и реализации, подобных крупны инвестиционных проектов социального назначения, требуется учитывать новые вызовы глобальных экономических процессов и негативные последствия финансово-экономических кризисов в мире [8, с.59]. Далее, процессы формирования государственной инвестиционной политики социально преобразования страны должно охватывать особенности оценки эффективности прогнозируемых и определяемых практичных инструментарий, критерий развития социальной инфраструктуры, социальных отношений и в целом социально-экономической инфраструктуры. Тем более, мировой опыт отдельных стран и регионов свидетельствует о целесообразности применения новых социальноэкономических механизмов в условиях структурных изменений экономики. Так, в период осуществления глубокого экономического преобразования системного характера, в 1990-ых годах в Центральной и Восточной Европе и в странах бывшей СССР потребовалось кардинальные перемены по модернизацию социальной политики, вновь созданной уже независимых государств или стран, которые отказались продолжить идеи и критерии социалистического строя [9]. Дело в том, что в этот период решающим факторам в формировании и развитии социальной стратегии постсоциалистических республик стали механизмы и критерии рыночных преобразований, которые потребовались глубокие структурные и качественные изменения, осуществления масштабной социально-экономической реформы. По результатам пройденных этапов и времени, можно отметить, что страны Центральной и Восточной Европы - таких как Венгрия, Чехия, Польша, Словакия и Словения не только преодолели многочисленных проблем наследующих от социалистического режима, в то же время успешно справились с трудностями структурных и системных преобразований и в результате чего обеспечили устойчивый экономический подъем, углубление рыночных отношений и создание более справедливых социальных стратегий. Однако и в этих странах до сих пор остались не решенные вопросы и проблемы по совершенствованию социальной политики и социальной стратегии. По мнению специалистов и исследователей, эти страны лишь вплотную приблизились к тому уровню экономического развития, который определял их положения до начало системной трансформаций и поэтому требуется последовательные решения оставшиеся барьеры по повышению социальноэкономического уровня и обеспечения существенного улучшения жизненного благосостояния населения своей страны [10]. Особый интерес вызывает существующие подходы, в том числе государственные механизмы формирования и развития социальной стратегии в бывших республиках СССР, где и состоялся и Азербайджан. Так, в России в период структурных преобразований и основные фазы экономических реформ вопросы социальной политики и основные критерии социальной стратегии постоянно находились в центре государственного регулирования и институциональных действий. Отмечается роль государство и усиление его деятельности в процессах формирования и реализации социальной стратегии в вопросах бесперебойного обеспечения необходимыми ресурсами, в том числе финансовыми ресурсами для интенсификации социально-экономического развития страны. Принципиальная особенность современной системы стратегического планирования и формирования социальной стратегии состоит в том, что уже не просчете и недостатки рынка, а ключевые, долговременные интересы развития рыночной системы, хозяйствования настоятельно требует широкого использования действенных рычагов государственного воздействия на долговременные тенденции, социальноэкономического развития, а также на источники экономического роста и инструменты их использования [11, с.193]. При этом очень важно, что в период формирования и оптимизации социальных стратегий страны учитывались необходимые условия для обеспечения достойных условий жизни населения, повышения в качестве быта и предоставления достойных 


\begin{tabular}{|c|c|c|c|c|c|c|}
\hline \multirow{4}{*}{ Impact Factor: } & ISRA (India) & $=3.117$ & SIS (USA) & $=0.912$ & ICV (Poland) & $=6.630$ \\
\hline & ISI (Dubai, UAE & $=0.829$ & РИНЦ (Russia) & $=0.156$ & PIF (India) & $=1.940$ \\
\hline & GIF (Australia) & $=0.564$ & ESJI (KZ) & $=\mathbf{5 . 0 1 5}$ & IBI (India) & $=4.260$ \\
\hline & JIF & $=1.500$ & SJIF (Morocco) & $=5.667$ & OAJI (USA) & $=0.350$ \\
\hline
\end{tabular}

рабочих мест, эффективность труда, работоспособность основных законов, адекватность социальных инфраструктур, интенсивность и эффективность потребительских рынков, обеспечение основными видами пищевых продукций и комплексного рассмотрения пищевой безопасности, доступности важными видами пищевых продукций, стратегические отношения соблюдения стандартов по экологии и охранения окружающей среды, развития «зеленой» экономики и режима сбережения энергоресурсов, альтернативных источников электроэнергии, улучшения инвестиционно-инновационной сферы и среды, создания благоприятных условий развития предпринимательской деятельности, бизнеса и стимулирования активного перехода иностранных инвесторов в страны и прочее. При развитии социальных стратегий и реализации социально-экономических приоритетов особо требуется совершенствования фискальных механизмов, в том числе налоговых инструментарий по моделированию и сбалансированности эффективности существующих механизмов социальноэкономического развития страны. По мнению исследователя И.Л.Юрзинова налоговая политика страны в качестве важного механизма в процессах развития социальной стратегии и управления социально экономическим развитиям должно представлять собой компромисс экономических интересов всех субъектов налоговой политики исходя из роли налогов в системе экономических отношений и с учетом особенностей критерий социальноэкономического развития страны, который могло бы обеспечить удовлетворения общественных потребностей до обеспечения решений системы задач социально-экономического развития общество при условии сохранения и роста экономического потенциала, хозяйствующих субъектов [12, с. 78]. Тем более, в России за последнее десятилетия проводились системные работы оптимизации социальных стратегий и рассматривались долгосрочные перспективы на этом направлении. Так Указом Президента России от 7 мая 2018 года «О национальных целях и стратегических задачах развития Российской Федерации на период до 2024 года», определены главные механизмы, приоритеты и подходы социального развития и социальной стратегии страны [13]. Далее, с постановлением правительства России от 27 сентября 2018 года разработано основные прогнозы социальноэкономического развития на период до 2024 года, где определились важнейшие механизмы и инструментарии, принципы и критерии социальной стратегии в долгосрочном перспективе [14]. Отмечается, что приоритетные сферы структурных реформ в настоящее время практически идентичны для ведущих стран: это развития человеческого капитала, прежде всего образования и здравоохранения, инфраструктуру, совершенствование государственного управления [15]. Аналогичные и в какой-то степени схожие подходы формирования и развития социальной стратегии происходит в основных торговоэкономических партеров Азербайджана среди стран бывшего СССР, ныне объединяющиеся в СНГ - Казахстан и Беларусь. В Казахстане в числе главных подходов и критерий по формированию и развитию социальной стратегии, особое место отводиться на реализацию сбалансированной государственной социальной политики во всех сферах, применения модели технико-инновационносервисной экономики исходя место Казахстана в системе международного разделения труда, уровня синхронизации технико-экономического развития с глобальными тенденциями экономического роста ведущих промышленно развитых стран с учетом обсечения роста основных индикаторов социальных и экономических показателей, реализация перспективных и стратегических планов социально-экономического развития [16]. В Казахстане определены новые принципы социальной политики страны в рамках «Стратегия-2050» [17]. В Беларуси в деятельности правительства очень обширно предоставлено социально ориентированные механизмы и инструментарии. В национальной стратегии устойчивого социальноэкономического развития республики Беларусь на период до 2020 года отмечается, что на основе социальной стратегии и устойчивого развития страны заложено мировые тенденции экономического развития, основные компоненты модели устойчивого развития и императивы под девизом «человек - окружающая средаэкономика» [18].

Считаем, что в Азербайджане при формировании и развития социальной стратегии в условиях структурных изменений и глобальных воздействий нет необходимости слепого копирования и трансфера мирового опыта. Необходимо учитывать исторические аспекты развития общество и экономики, традиционные сферы занятости, обычаи и обряды, особенности национальных ценностей, потенциал перспективных секторов экономики страны. Особые подходы должны проявиться в сбалансированном формировании социальных стратегий Азербайджана с учетом глобальных социально-экономических вызовов в долгосрочной перспективе. В Азербайджане проводиться масштабные социальные политики, которые способствуют повышению жизненного 


\begin{tabular}{|c|c|c|c|c|c|c|}
\hline \multirow{4}{*}{ Impact Factor: } & ISRA (India) & $=3.117$ & SIS (USA) & $=0.912$ & ICV (Poland) & $=6.630$ \\
\hline & ISI (Dubai, UAE & $=0.829$ & РИНЦ (Russia) & $=0.156$ & PIF (India) & $=1.940$ \\
\hline & GIF (Australia) & $=0.564$ & ESJI (KZ) & $=\mathbf{5 . 0 1 5}$ & IBI (India) & $=4.260$ \\
\hline & JIF & $=1.500$ & SJIF (Morocco) & $=5.667$ & OAJI (USA) & $=0.350$ \\
\hline
\end{tabular}

уровня людей [19]. Утверждено стратегия занятости Азербайджана на 2019-2030 годы [20].

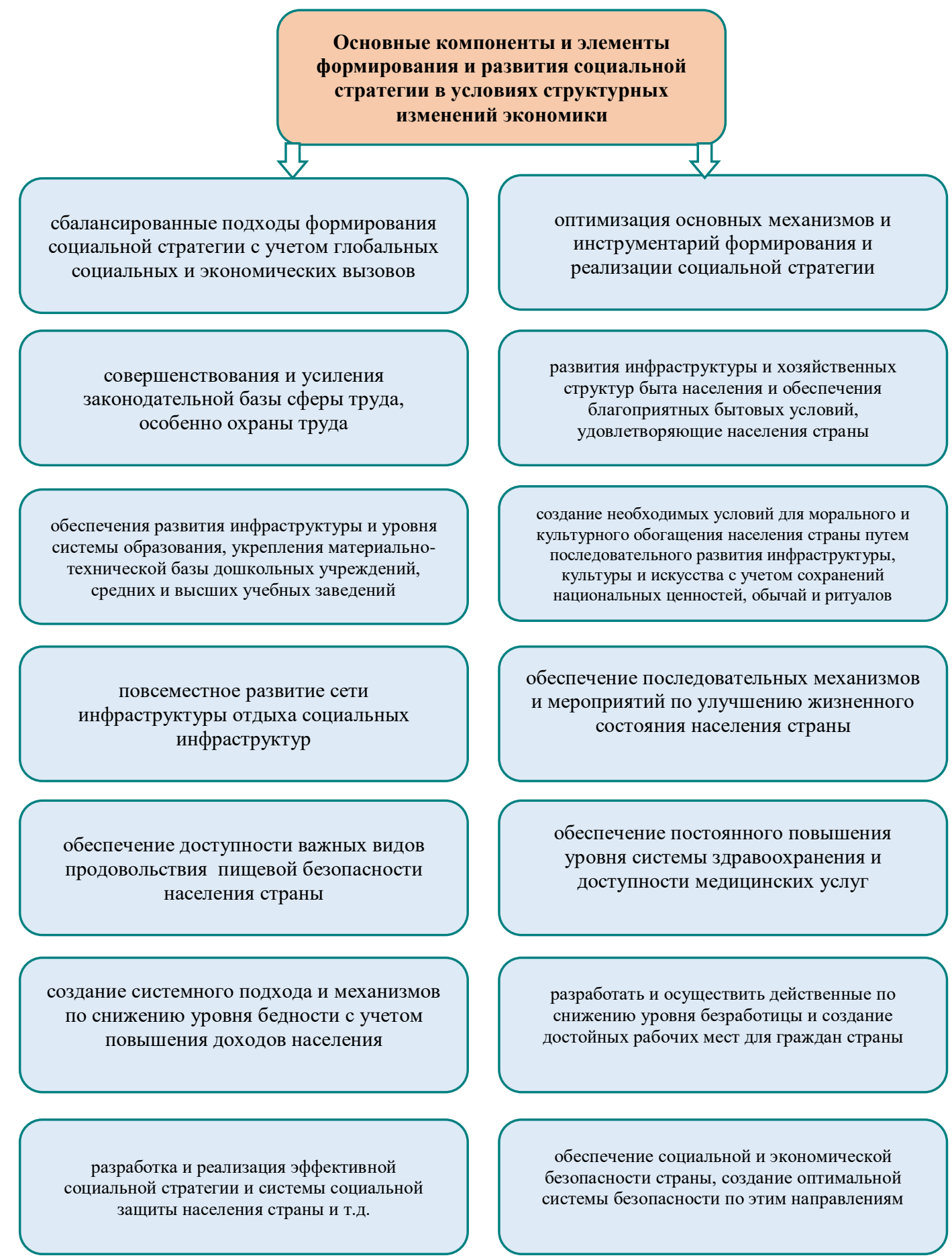

Рисунок 1. Блок-схема основных компонентов и элементов формирования и развития социальной стратегии в условиях структурных изменений экономики (разработано авторами на основе материалов исследования).

Наблюдается ускоренное развитие в Совершенствуется механизмы социальной экономической и социальной жизни страны. политики, расширяется сферы услуг, 


\begin{tabular}{|c|c|c|c|c|c|c|}
\hline \multirow{4}{*}{ Impact Factor: } & ISRA (India) & $=3.117$ & SIS (USA) & $=0.912$ & ICV (Poland) & $=6.630$ \\
\hline & ISI (Dubai, UAE & $=0.829$ & РИНЦ (Russia & $=0.156$ & PIF (India) & $=1.940$ \\
\hline & GIF (Australia) & $=0.564$ & ESJI (KZ) & $=\mathbf{5 . 0 1 5}$ & IBI (India) & $=4.260$ \\
\hline & JIF & $=1.500$ & SJIF (Morocco & $=5.667$ & OAJI (USA) & $=0.350$ \\
\hline
\end{tabular}

увеличиваются доходы и заработная плата населения [21]. Каждым годом повышение уровня и качества жизни граждан все больше является основной целью социальной политики Азербайджана в условиях глобальной нестабильности [22]. Эти тенденции отмечены и со стороны международных организаций в том числе высокопоставленными лицами ООН. Так, по мнению высокопоставленного чиновника $\mathrm{OOH}$, решение экономических вопросов в Азербайджане является образцовым и в стране осуществляется комплексные мероприятии устойчивого развития страны в долгосрочной перспективе [23].

На Рисунке 1 дано Блок-схема основных компонентов и элементов формирования и развития социальной стратегии в условиях структурных изменений экономики.

\section{Conclusion}

Таким образом, анализ Рисунка 1 и материалы исследования позволяют предположить, что в ближайшей перспективе существенно повыситься актуальности совершенствования важных механизмов и практичных инструментарий формирования социальной стратегии страны в условиях структурных изменений экономики. При этом в числе серьезных проблем и задач окажется комплексные подходы и решение социальноэкономических проблем, улучшение жизненного состояния, быта, обеспечения гармоничного и сбалансированного развития общество и экономики, раскрыта потенциал человеческого потенциала, улучшения инвестиционноинновационного климата и среды, доступность важным видам пищевой продукции, уменьшение бедности и безработицы, развития системы здравоохранения и образования, сети социальной инфраструктуры, которое будет составлять основные системообразующие компоненты социальной стратегии страны в долгосрочной перспективе.

\section{References:}

1. (n.d.). Cocial'naja politika gosudarstvajekonomicheskogo teorija. Retrieved 2019, from http://be5.biz.ekonomika/e012/26.html

2. (n.d.). Strategija razvitija jekonomiki $i$ optimizacii social'noj politiki. Retrieved 2019, from http://moldovenii.md/ru

3. (n.d.). Cocial'naja politika gosudarstva kak instrument realizacii strategii social'nojekonomicheskogo razvitija. Retrieved 2019, from http://cyberleninka.ru

4. (n.d.). Cocial'naja politika gosudarstva: Cocial'naja politika gosudarstvaskoordinirovannyh mer. Retrieved 2019, from http://economics.studio

5. (n.d.). Strategija social'no-jekonomicheskogo razvitija. Retrieved 2019, from http://knigi.news

6. Shlenskova, E. S. (n.d.). Formirovanie sistemy strategicheskogo upravlenija social'nojekonomicheskim razvitiem otraslevyh sostavljajushhih sfery uslug. Dis. d-ra jekon. nauk. (p.299). Sankt-Peterburg.

7. Dokal'skaja, V. K. (n.d.). Upravlenie social'nojekonomicheskim razvitiem regionov: teorija $\mathrm{i}$ metodologija. Dis. d-ra jekon. nauk. (p.388). Orel.

8. Gajzatullin, R. R. (n.d.). Formirovanie gosudarstvennoj investicionnoj politiki social'no-jekonomicheskogo razvitija $i$ ee finansovoe obespechenie. Dis. d-ra jekon. nauk. (p.412). Kazan'.

9. (2017). Covremennaja social'naja politika stran evropejskogo sojuza: problemy i perspektivy razvitija. Juridicheskogo nauka, №3, 166-172.

10. Markov, D. S. (n.d.). Problemy perehoda $k$ novoj modeli social'no-jekonomicheskogo razvitija $v$ stranah Central'noj $i$ Vostochnoj Evropy. Dis. d-ra jekon. nauk. (p.389). Moskva.

11. Krymov, V. B. (n.d.). Strategicheskoe planirovanie $v$ sisteme upravlenija social'nojekonomicheskim razvitiem sub\#ekta Rossijskoj Federacii. Dis. d-ra jekon. nauk. (p.421). Moskva.

12. Jurzinova, I. L. (n.d.). Nalogovaja politika kak instrument upravlenija social'nojekonomicheskim razvitiem Rossijskoj Federacii. Dis. d-ra jekon. nauk. (p.391). Moskva. 


\begin{tabular}{|c|c|c|c|c|c|c|}
\hline \multirow{4}{*}{ Impact Factor: } & ISRA (India) & $=3.117$ & SIS (USA) & $=0.912$ & ICV (Poland) & $=6.630$ \\
\hline & ISI (Dubai, UAE & $=0.829$ & РИНЦ (Russia & $=0.156$ & PIF (India) & $=1.940$ \\
\hline & GIF (Australia) & $=0.564$ & ESJI (KZ) & $=\mathbf{5 . 0 1 5}$ & IBI (India) & $=4.260$ \\
\hline & JIF & $=1.500$ & SJIF (Morocco & $=5.667$ & OAJI (USA) & $=0.350$ \\
\hline
\end{tabular}

13. (2018). Ukaza Prezidenta Rossii ot 7 maja 2018 goda №204 «O nacional'nyh celjah i strategicheskih zadachah razvitija Rossijskoj Federacii na period do 2024 goda». prognoze social'no-jekonomicheskogo razvitija Rossijskoj Federacii na period do 2024 goda. Utverzhdeno na zasedanii Pravitel'stva 27 sentjabrja 2018 goda.

14. Medvedev, D. A. (n.d.). Rossija-2024: Strategija social'no-jekonomicheskogo razvitija. Retrieved 2019, from http://government.ru

15. Bejsenbaev, A. A. (n.d.). Social'nojekonomicheskogo razvitija regionov Respubliki Kazahstan. Dis. d-ra jekon. nauk. (p.325). Sankt-Peterburg.

16. Kanafina, G. E. (2013). Novye principy social'noj politiki Kazahstan poslaniju prezidenta narodu Kazahstana «strategija2050». Almaty.

17. (n.d.). Nacional'naja strategija ustojchivogo razvitija (NSUR) na period do 2020 goda.
Organizacija ob\#edinennyh nacij v Belarusi. Retrieved 2019, from http://un.by/

18. Ahmedov, A. (n.d.). Pravitel'stvo Azerbajdzhana uspeshno provodit masshtabnuju social'nuju politiku Il'hama Alieva. Retrieved 2019, from https://novosti.az

19. (n.d.). V Azerbajdzhane utverzhdena strategija zanjatosti do 2031 goda. Retrieved 2019, from http://abc.az

20. Abdullaeva, R. S. (n.d.). Social'naja politika v Azerbajdzhane: Sovremennoe sostojanie $i$ napravlenija razvitija. Retrieved 2019, from https://cyberleninka.ru

21. (n.d.). Social'noe blagosostojanie naroda - odin iz glavnyh prioritetov gosudarstvennoj politiki $v$ Azerbajdzhane. Retrieved 2019, from https://azertag.az

22. Gendirektor OON (n.d.). Reshenie social'nojekonomicheskih voprosov $v$ Azerbajdzhane javljaetsja obrazcovym. Retrieved 2019, from http://vzgylad.az 